Pain Physician. 2005;8:67-72, ISSN 1533-3159

\title{
Fluoroscopically Guided Cervical Prolotherapy FOR INSTABILITY WITH BLINDED Pre and Post Radiographic Reading
}

\author{
Christopher J. Centeno, MD, James Elliott, MSPT, PhDc, Whitney L. Elkins, MPH, and
}

Michael Freeman, PhD, MPH, DC

Background: Several authors have postulated that cervical instability is a major cause of traumatic spinal pain.

Objective: The purpose of this prospective case series study $(n=6)$ was to determine if proliferant injections have an effect on cervical translation as measured by a blinded reader.

Design: This study was a prospective case series. Study participants were selected from patients seen for the primary complaint of Motor Vehicle Collision related neck pain in a private sub-specialty pain clinic.

Methods: Flexion and extension views were obtained by standard radiographs taken with a C-Arm fluoroscope under Valium sedation. Patients with more than $2.7 \mathrm{~mm}$ of absolute cervical translation and at least
$50 \%$ reduction of cervical and referred pain with a two day rigid cervical immobilization test were admitted into the study. Participants underwent 3 prolotherapy injections at all sites that demonstrated translation. The difference in means between pre-test and post-test measurements (flexion translation, extension translation, and pain VAS scores) were assessed by a Wilcoxon signed ranks test (alpha $=0.05)$.

Results: The mean post-test VAS score $(M=3.83, S D=2.3, t=2.889)$ was significantly less $(p=0.04)$ than the mean pre-test VAS score $(M=5.75, S D=1.94)$. The correlation between difference in mean extension at $\mathrm{C}_{2}-3$ and $\mathrm{C}_{5}-6$ and difference in mean extension was significant ( $r h o=0.89, p=0.02$ and $\mathrm{rho}=0.85, p=0.03$ respectively). Difference in mean flexion at $\mathrm{C}_{3-4}$ and $\mathrm{C}_{4-5}$ was significantly correlated with difference in mean flexion $(r h o=0.88, p=0.02$ and $r h o=0.941$, $\mathrm{p}<0.01$ respectively).

Conclusions: The results of this study demonstrate statistically significant correlations between proliferant injections, a reduction of both cervical flexion and extension translation, as well as a reduction in pain VAS score. Since patients with traumatic cervical instability have few viable treatment options other than surgical fusion, cervical proliferant injections under C-Arm fluoroscope may be a viable treatment option.

Keywords: Prolotherapy, cervical instability, flexion, extension, injection, whiplash, neck
Several authors have postulated that instability is a major cause of traumatic spinal pain. Dvorak (1) reported increased upper and mid-cervical hypermobility in a cervical spine trauma group in comparison of trauma versus degenerative pain. In addition, Panjabi et al (2) have reported a biomechanical investigation of increases in the "neutral zone" of the cervical spine as a result of trauma, with significant increases noted in the neutral zone with experimental accelerations of as low as $4.5 \mathrm{~g}$. Most recently, Kristjansson et al (3) have published a report showing that whiplash patients had

From Spinal Injury Foundation Westminster, Colorado. Address Correspondence: Christopher J. Centeno, MD, 11080 Circle Point Road, Suite 140, Westminster, CO 80020

Disclaimer: Nothing of monetary value was received in the preparation of this manuscript.

Conflict of Interest: None

Acknowledgement:

Manuscript received on 8/4/2004

First revision submitted on 10/04/2004

Second revision submitted on 11/02/2004

Accepted for publication on 11/05/2004. objectively increased translational and rotational movements when compared with controls.

The idea that instability may be associated with pain and neurologic compromise is not new. Grob (4) performed an experimental protocol on patients with cervical soft tissue injury by applying an external fixator in random patterns. The external fixation applied in a single blinded fashion over presumed unstable segments gave pain relief, while fixation over normal segments provided no relief. Ebraheim et al (5) has determined that lower cervical translation in flexion can have serious negative impacts on spinal canal diameter. In addition, spinal canal volume in normal patients is reduced by both flexion and extension (6). Normal foraminal width in the cervical spine is on the order of millimeters (7). In addition, static foraminal widths decrease significantly with age (8).

The standard for measuring cervical instability is usually considered to be cervical flexion extension radiography. How- ever, Dvorak et al (1) have determined that routine non-stress films may have a significant false-negative rate. This study confirmed that routine active flexion-extension radiographs missed some $39 \%$ of levels determined to be unstable on passive examination with over-pressure (9). White et al (10) have produced normal values for flexion-extension radiography. White and Panjabi (10) studied an isolated cervical segment by cutting ligamentous constraints and determining movement. They determined that the segment became unstable at $2.7 \mathrm{~mm}$ of absolute movement or $3.5 \mathrm{~mm}$ of magnified movement on a 72 inch lateral x-ray. Since that time, normal studies in-vivo have been performed. Knopp et al (11) defined abnormal motion as more than $2 \mathrm{~mm}$ of movement at end range flexion. Lin et al (12) also published a series of 100 normals with population norms for patients. If one factors out the "hypermobile" individuals (defined by Lin et al as having significant translation at the C2-C3 level), the amount of normal translation was al- 
ways less than $1 \mathrm{~mm}$.

The purpose of this study was to determine if proliferant injections have an effect on objectively measured cervical translation as measured by a blinded reader.

\section{Methods}

This was a prospective case series study of patients seen for the primary complaint of Motor Vehicle Collision related neck pain in a private sub-specialty pain clinic.

Inclusion criteria were:

- Prior history of an motor vehicle collision (MVC)

- Ongoing disability resulting from cervical spine pain for longer than six (6) months related to the MVC

- Cervical flexion extension $\mathrm{x}$-rays that were abnormal either based on the Knopp criteria ( $2 \mathrm{~mm}$ or more translation at end range flexion) or the White and Panjabi criteria $(2.7 \mathrm{~mm}$ or more of absolute cervical translation)

- $50 \%$ or greater reduction of pain with 48 hour rigid cervical immobilization

- Failure of conservative management (physical therapy and or chiropractic and or alternative care)

Exclusion criteria were:

- History of previous neck pain with a neck injury

- Connective tissue disease

- Rheumatoid arthritis

- Diabetes I or II

- Inflammatory arthritis.

Eligible patients $(n=6)$ were identified from consecutive patients presenting for care who were found to be unstable. The setting was a specialty pain management private practice. The Institutional Review Board (IRB) approval was obtained for the pilot study through a Department of Health and Human Services registered IRB (The Spinal Injury Foundation). Informed consent was obtained.

Flexion and extension views were obtained by standard radiographs taken with a C-Arm fluoroscope with diazepam sedation (10 mg Oral), overpressure into end range flexion and extension, and stabilization of the torso. A radiographic ruler was included in the $\mathrm{x}$-ray field in the same plane as the c-spine for accuracy and to rule out magnification effects between radiographs. Flexion and extension translation were measured by comparing translation to the radiographic ruler and then was recording these measurements in millimeters.

Patients with more than $2.7 \mathrm{~mm}$ of absolute cervical translation $(3.5 \mathrm{~mm}$ of magnified movement on a 72 inch lateral $\mathrm{x}$-ray) and at least $50 \%$ reduction of cervical and referred pain with a two day rigid cervical immobilization test were admitted into the study. Six consecutive patients with 11 unstable levels met the inclusion criteria. A blinded reader was used to assess instability before and after proliferant injections. Blinding was accomplished by identifying the films with only a letters and numbers. The reader then recorded the translation in maximum flexion to maximum extension from posterior inferior corner to adjacent posterior superior corner of the cervical vertebra.

Patients underwent 3 prolotherapy series at all sites that demonstrated translation. The number of injections per series were determined by applying the Hackett technique to all unstable levels. The patient was placed prone on an $\mathrm{x}$-ray table and a C-Arm fluoroscope was used to image the c-spine in an AP view. Cephalad tilt was applied to move the skull base out of the field of view. After IV anesthesia was applied, a 25 gauge two or three inch spinal needle (depending on patient body habitus) was used to perform the injections. Injectate consisted of a final concentration of $12.5 \%$ dextrose diluted with normal saline and 1-2 cc of lidocaine per $10 \mathrm{cc}$ added for patient comfort. At the

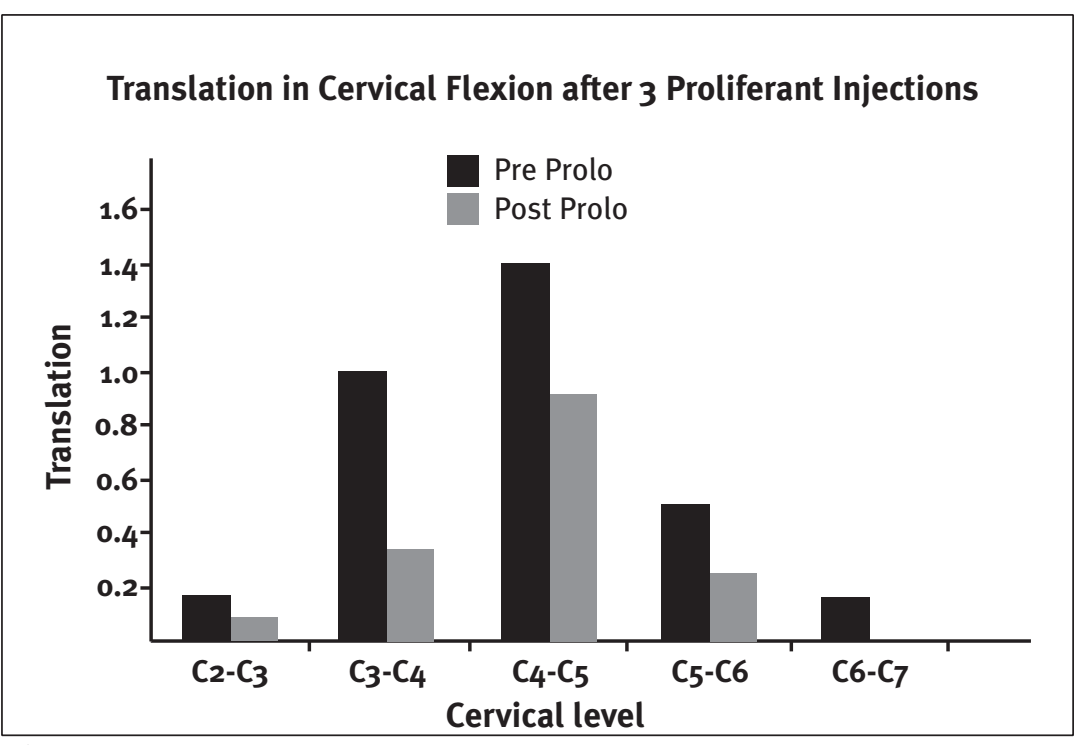

Fig 1. Translation in cervical flexion after 3 proliferant injections unstable levels, several structures were injected when bone was contacted at the unstable level(s) as well as above and below these levels. These structures included: the spinous processes, lamina, and posterior elements according to the technique outlined by Hackett (13). The C-Arm was used to confirm needle position prior to injection

Outcome measures included average neck pain on a modified VAS (1-10) Scale. This was administered 2-4 weeks prior to the injections and one month post injection. Patients refrained from all other types of care for the duration of the study.

Since all variables were not normally distributed, the difference in means between pre-test and post-test measurements were assessed by a Wilcoxon signed ranks test $($ alpha $=0.05)$. Bivariate correlations using Spearman's rho were computed among the four outcome measures: mean difference flexion, mean difference in extension, mean difference in overall translation, and mean difference in pain (alpha $=0.05)$, as well as with all mean translation measures at individual levels of injection for both flexion and extension.

\section{RESULTS}

Figure 1 and 2 below show the changes in translation in both flexion and extension for all patients by vertebral level as a result of the treatment. Perhaps the most striking feature is the more dramatic effect of the treatment in flexion ver- 


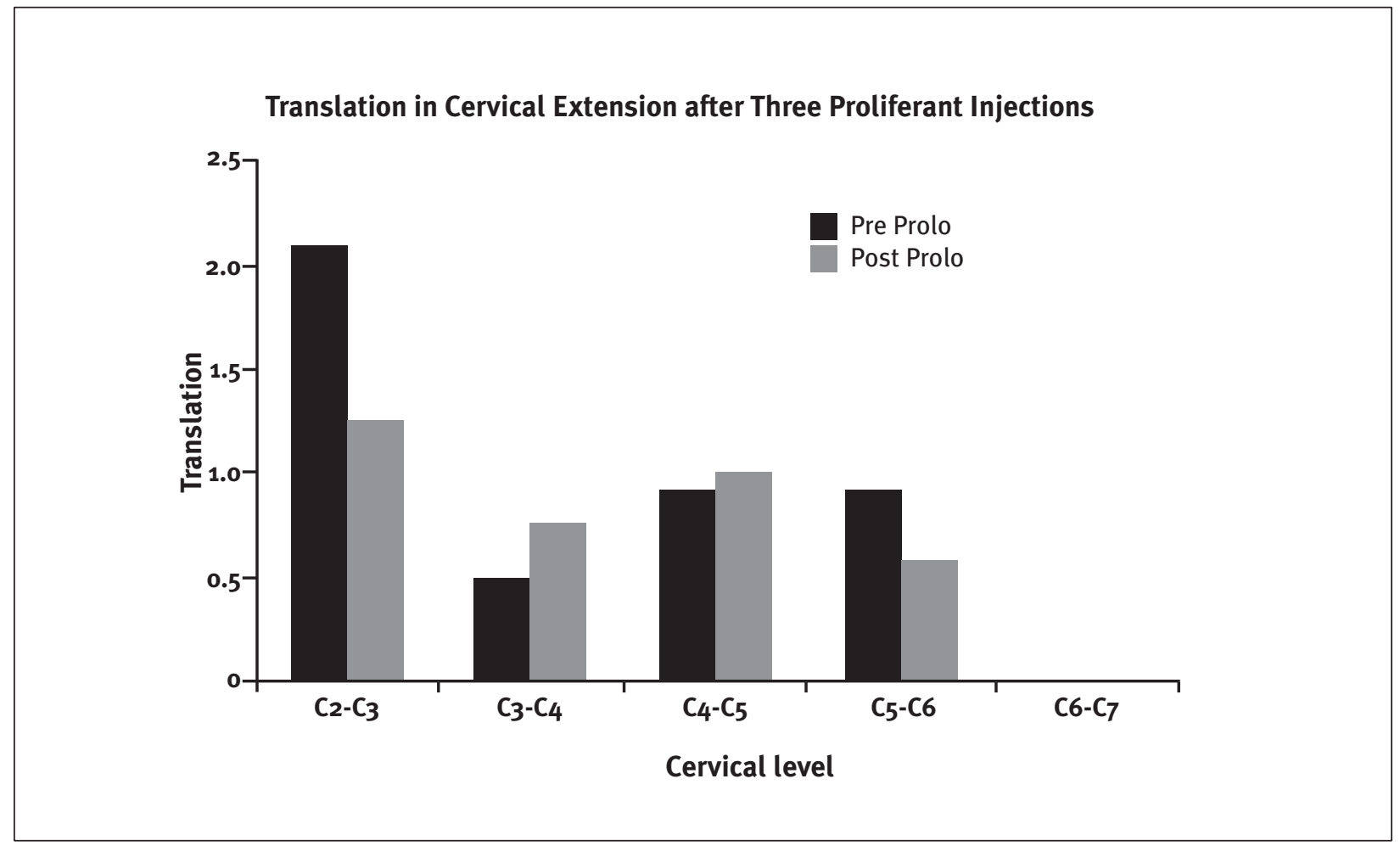

Fig 2. Translation in Cervical Extension after 3 Proliferant Injections

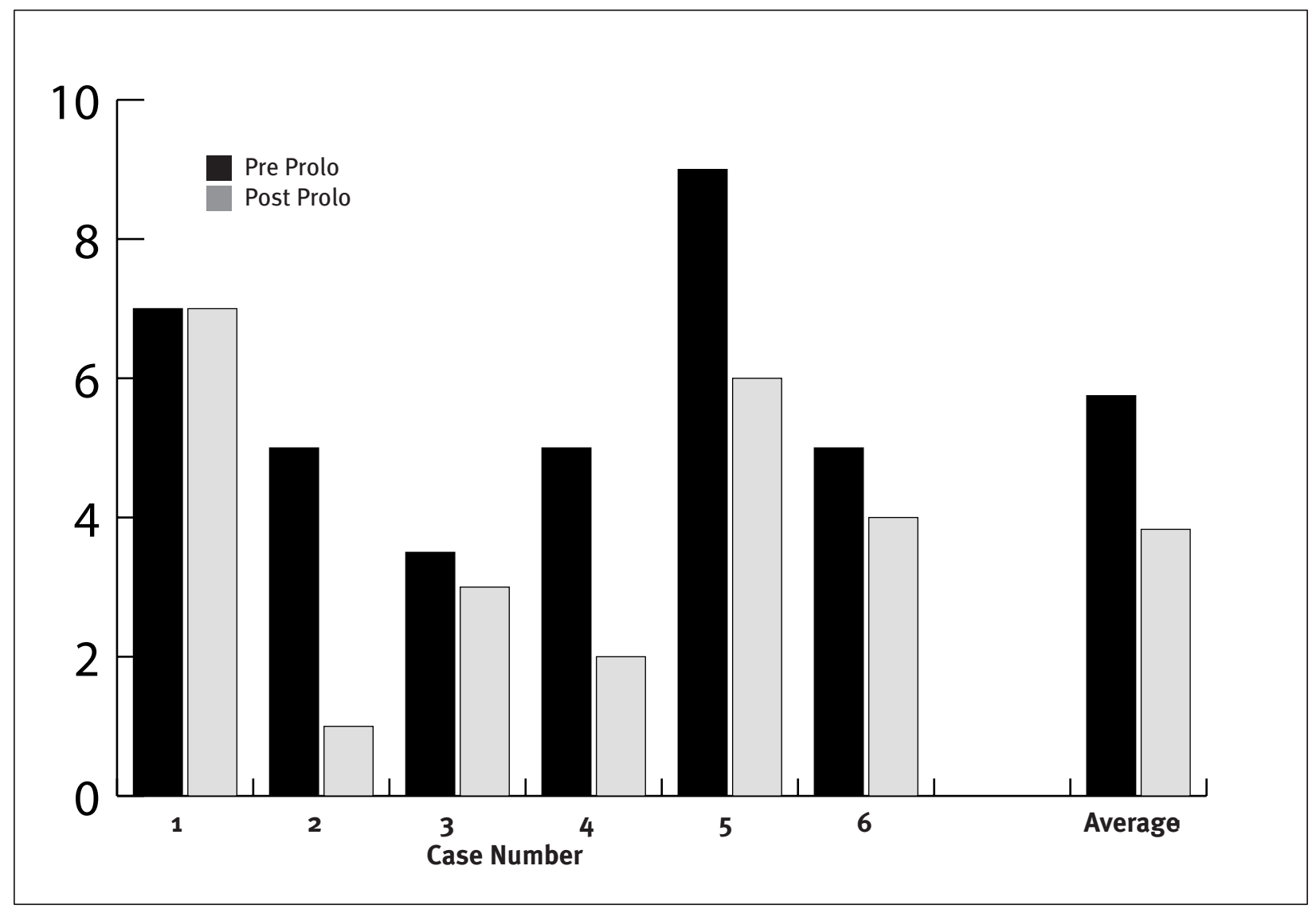

Fig 3. Average VAS scores after 3 cervical proliferant injections 


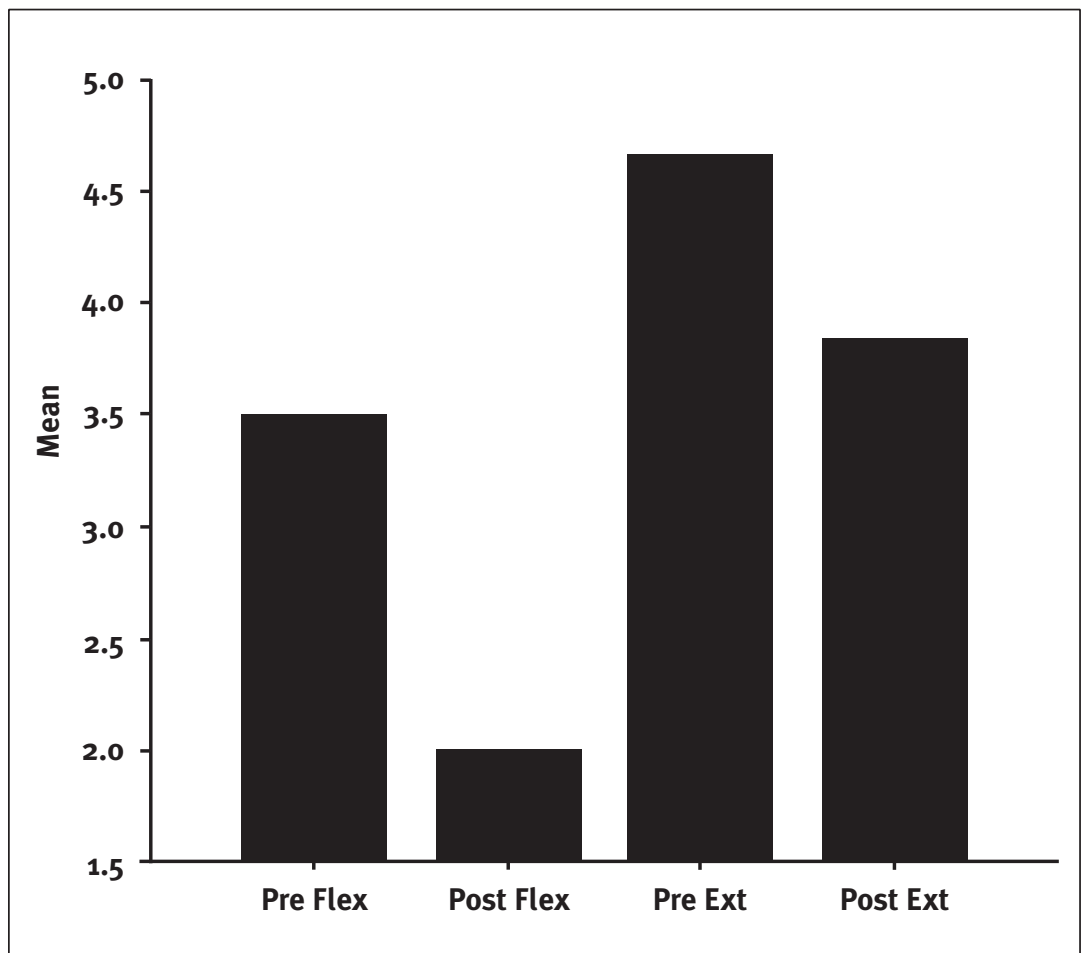

Fig 4. Difference for mean translation for flexion and extension after 3 cervical proliferant injections

Table 1. Correlations of outcome measurements (Spearman's rho Correlation Coefficient)

\begin{tabular}{|l|c|c|c|c|}
\hline & Diff Trans & Diff Flex & Diff Ext & Diff Vas \\
\hline Diff Trans & 1.000 & $\left..943^{\star *}\right)$ & .147 & $\left.-.883^{*}\right)$ \\
\hline Diff Flex & $\left..943^{\star \star}\right)$ & 1.000 & .029 & -.794 \\
\hline Diff Ext & .147 & .029 & 1.000 & .076 \\
\hline Diff Vas & $\left.-.883^{\star}\right)$ & -.794 & .076 & 1.000 \\
\hline
\end{tabular}

** Correlation is significant at the 0.01 level (2-tailed).

* Correlation is significant at the 0.05 level (2-tailed).

Table 2. Correlations of outcome measurements with level of extension (Spearman's rho Correlation Coefficient)

\begin{tabular}{|l|c|c|c|c|c|c|c|}
\hline & $\begin{array}{c}\text { Diff Ext } \\
2-3\end{array}$ & $\begin{array}{c}\text { Diff Ext } \\
3-4\end{array}$ & $\begin{array}{c}\text { Diff Ext } \\
4-5\end{array}$ & $\begin{array}{c}\text { Diff Ext } \\
5-6\end{array}$ & Diff Ext & Diff Trans & Diff Vas \\
\hline $\begin{array}{l}\text { Diff Ext } \\
2-3\end{array}$ & 1.000 & .131 & $.822\left(^{\star}\right)$ & .671 & $.89\left(^{\star}\right)$ & .062 & .111 \\
\hline $\begin{array}{l}\text { Diff Ext } \\
3-4\end{array}$ & .131 & 1.000 & .180 & .220 & .469 & .334 & .063 \\
\hline $\begin{array}{l}\text { Diff Ext } \\
4-5\end{array}$ & $.822\left(^{\star}\right)$ & .180 & 1.000 & .612 & .783 & .507 & -.348 \\
\hline $\begin{array}{l}\text { Diff Ext } \\
5-6\end{array}$ & .671 & .220 & .612 & 1.000 & $.853\left(^{\star}\right)$ & .000 & .000 \\
\hline Diff Ext & $\left..890^{\star}\right)$ & .469 & .783 & $.853\left(^{\star}\right)$ & 1.000 & .147 & .076 \\
\hline Diff Trans & .062 & .334 & .507 & .000 & .147 & 1.000 & $\left.-.8833^{\star}\right)$ \\
\hline Diff Vas & .111 & .063 & -.348 & .000 & .076 & $-.883\left(^{\star}\right)$ & 1.000 \\
\hline
\end{tabular}

* Correlation is significant at the 0.05 level (2-tailed). sus extension. Figure 3 illustrates the decrease in pre-test and post-test VAS scores for individual cases and average scores.

A Wilcoxon signed ranks test was conducted to evaluate whether difference in mean flexion, difference in mean extension, and difference in mean pain VAS scores differed after treatment with cervical prolotherapy. Figure 4 shows the mean decrease in flexion translation (pretest to post-test) and extension (pre-test to post-test). These findings are not statistically significant due to the small number of test subjects ( $p=0.36$ and $p=0.40$ respectively).

However, the results did indicate that the mean post-test VAS score $(\mathrm{M}=$ 3.83, $\mathrm{SD}=2.3, \mathrm{t}=2.889)$ was significantly less $(\mathrm{p}=0.04)$ than the mean pre-test VAS score $(\mathrm{M}=5.75, \mathrm{SD}=1.94)$ as illustrated in Figure 3. Furthermore, difference in mean pain VAS correlated significantly with difference in mean translation (Table 1, rho $=-0.88, \mathrm{p}=0.02$ ). Additional correlation coefficients were computed among the four outcome measurements (as presented in Table 1) with difference in mean flexion and difference of mean translation correlating significantly $(\mathrm{rho}=0.94, \mathrm{p}<0.01)$.

Table 2 shows the correlation coefficients between the four outcome measures and difference in mean extension at each cervical level. The correlation between difference in mean extension at $\mathrm{C} 2$ 3 and C5-6 and difference in mean total extension for all levels was significant (rho=0.89, $\mathrm{p}=0.02$ and $\mathrm{rho}=0.85, \mathrm{p}=0.03$ respectively).

Table 3 shows the correlation coefficients between the four outcome measures and difference in mean flexion at each cervical level. Difference in mean flexion at C3-4 and C4-5 was significantly correlated with difference in mean total flexion for all levels $(\mathrm{rho}=0.88, \mathrm{p}=0.02$ and rho $=0.941, \mathrm{p}<0.01$ respectively).

\section{DisCUSSION}

This analysis demonstrated that the treatment decreases flexion translation more than extension translation. In addition, there was a correlation between decrease in translation and change in VAS score (pain relief). The type of effect seen here is important. Since this cervical prolotherapy technique only treats the posterior column of the spine and thus only treats the main ligamentous check to flexion, one would expect that translation 
Table 3. Correlations of outcome measurements with level of flexion (Spearman's rho Correlation Coefficient)

\begin{tabular}{|l|c|c|c|c|c|c|c|c|}
\hline & Diff Flex 2-3 & Diff Flex 3-4 & Diff Flex 4-5 & Diff Flex 5-6 & Diff Flex 6-7 & Diff Flex & Diff Trans & Diff Vas \\
\hline Diff Flex 2-3 & 1.000 & .348 & .718 & .000 & .000 & .676 & .676 & -.348 \\
\hline Diff Flex 3-4 & .348 & 1.000 & .719 & .674 & .674 & $.883\left(^{*}\right)$ & .794 & $\left.-.864^{*}\right)$ \\
\hline Diff Flex 4-5 & .718 & .719 & 1.000 & .696 & .696 & $\left..941^{* *}\right)$ & $\left..941^{* *}\right)$ & -.719 \\
\hline Diff Flex 5-6 & .000 & .674 & .696 & 1.000 & $1.000\left(^{* *}\right)$ & .655 & .655 & -.674 \\
\hline Diff Flex 6-7 & .000 & .674 & .696 & $1.000\left(^{* *}\right)$ & 1.000 & .655 & .655 & -.674 \\
\hline Diff Flex & .676 & $.883\left(^{*}\right)$ & $.941\left(^{* *}\right)$ & .655 & .655 & 1.000 & $.943\left(^{* *}\right)$ & -.794 \\
\hline Diff Trans & .676 & .794 & $.941\left(^{* *}\right)$ & .655 & .655 & $.943\left(^{* *}\right)$ & 1.000 & $\left.-.883^{*}\right)$ \\
\hline Diff Vas & -.348 & $-.864\left(^{*}\right)$ & -.719 & -.674 & -.674 & -.794 & $\left.-.883^{*}\right)$ & 1.000 \\
\hline
\end{tabular}

* Correlation is significant at the 0.05 level (2-tailed).

** Correlation is significant at the 0.01 level (2-tailed).

in flexion would be more impacted than translation in extension. Since the anterior column was not treated, it is not surprising extension showed smaller reductions in translation. This agreement between objective experimental data at 11 levels and the areas treated suggests that cervical prolotherapy likely had an impact on segmental translation among our study subjects.

The use of proliferants to treat pain and instability has a long history. In a double blind study, Liu et al (14) injected the medial collateral ligament on rabbits and showed that through repeated injections of $5 \%$ sodium morrhuate at the fibroosseous attachments, the bone-ligament-bone junction strength was significantly increased by $28 \%$, ligament mass increased by $44 \%$, and thickness increased by $27 \%$ when compared to saline (14). Highly significant increases in the diameter of collagen fibrils in the experimental ligaments vs. controls were demonstrated by morphometric analysis of electron micrographs.

In a double blind clinical study by Ongley et al (15), 81 patients with chronic lower-back pain were injected with proliferants. It was found that significant improvement was seen in more than $50 \%$ of patients injected with Dextrose/Phenol/ Glycerin vs. saline. In addition, Ongley demonstrated a significant statistical improvement in five patients treated for painful instability of the knees with prolotherapy. Three-dimensional computerized goniometry integrated with force measurements were used to collect ligament stability data. More successful results were seen by Bourdeau (16) who published a 5-year retrospective survey of patients with lower back pain treated with prolotherapy. In the study, 70\% (17 pa- tients) reported a successful treatment.

Klein et al (17) was able to histologically document proliferation and regeneration of ligaments in human patients in response to injections of the DPG solution. In addition Klein et al (17) recorded decreased pain and increased range of motion via computerized inclinometry.

In a study of 43 patients with chronic sacroiliac strain, Schwartz et al (18) gave patients a series of three proliferant injections at biweekly intervals. An improvement was seen in all but three patients; $95 \%$ improvement was reported in 20 patients $66 \%$ improvement was seen in 4 patients, and 10 patients reported recurrence. With this, Schwartz concluded that induced proliferation of collagen and dense connective tissue of the ligament is associated with a reduction of painful subluxations.

Klein et al (19) presented a double blind clinical study of 79 patients who had previously failed to respond positively to conservative treatment for chronic lower back pain. The subjects were randomly assigned to a test group to receive a series of six injections into the posterior sacroiliac and interspinous ligaments, fascia, and facet capsules of the low back from L-4 to the sacrum of either lidocaine/saline or lidocaine/DPG solution in a double blind fashion at weekly intervals. For comparative purposes, all patients underwent pretreatment MRI of CT scans. Following the conclusion of injections patients were evaluated after 6 months using several criteria: visual analog, disability, pain grid scored, and with objective computerized triaxial tests of lumbar function. In the proliferant group, 30 of the 39 patients randomly assigned achieved a 50\% or greater decrease in pain or disability scored compared to 21 of 40 in the li- docaine group ( $\mathrm{p}=0.042)$. In addition, improvements were seen in visual ana$\log (\mathrm{p}=0.056)$, disability $(\mathrm{p}=0.068)$, and pain grid scores $(\mathrm{p}=0.025)$ for the proliferant group.

A double blind, placebo controlled study demonstrated the benefits of $10 \%$ dextrose with lidocaine in knee osteoarthritis with anterior cruciate ligament laxity (20). Goniometric flexion measurements improved by $12.8 \%(\mathrm{p}=0.005)$ and anterior displacement difference improved by $57 \%(\mathrm{p}=0.025)$. Dextrose treated knees improved in many measured categories: pain decreased 44\%, swelling complaints decreased 63\%, knee buckling frequency decreased $85 \%$, and flexion range had an increase of $14^{\circ}$ after a 12 month (six injection) treatment. Thus, it was concluded that stimulated growth factors and regeneration occurred after proliferant injection with $10 \%$ dextrose solution. This resulted in statistically significant clinical improvements in knee osteoarthritis.

While the small number of patients in this study precludes large scale statistical analysis, the correlational statistics do demonstrate significance in the directions hypothesized. This may prove to be an important correlation, as there are little published data on cervical translation and pain complaints.

Although other authors have published outcome studies on cervical prolotherapy $(21,22)$, this paper represents the first report of image guided cervical prolotherapy with objective changes measured radiographically.

\section{Conclusion}

The results of this study demonstrate statistically significant correlations between proliferant injections, a reduc- 
tion of both cervical flexion and extension translation, as well as a reduction in pain VAS score. Since patients with traumatic cervical instability have few viable treatment options other than surgical fusion, cervical proliferant injections under C-Arm fluoroscope may be a viable treatment option.

\section{Author Affiliation \\ Christopher J. Centeno, MD \\ Medical Director \\ Spinal Injury Foundation \\ 11080 Circle Point Road, Suite 140 \\ Westminster, CO 80020 \\ E-mail: centenooffice@centenoclini \\ c.com \\ James Elliott, MSPT, PhDc \\ Gunn Certified IMS Practitioner \\ Spinal Injury Foundation \\ 11080 Circle Point Road, Suite 140 \\ Westminster, CO 80020 \\ Whitney L. Elkins, MPH \\ Clinical Research Coordinator \\ Spinal Injury Foundation \\ 11080 Circle Point Road, Suite 140 \\ Westminster, CO 80020 \\ wwelkins@spinalinjuryfoundation. org \\ Michael Freeman, PhD, MPH, DC \\ Clinical Assistant Professor \\ Spinal Injury Foundation \\ 11080 Circle Point Road, Suite 140 \\ Westminster, CO 80020 \\ drmfreeman@earthlink.net}

\section{REFERENCES}

1. Dvorak J, Panjabi MM, Grob D et al. Clin ical validation of functional flexion/ extension radiographs of the cervical spine. Spine 1993; 18:120-127.

2. Panjabi MM, Nibu K, Cholewicki J. Whiplash injuries and the potential for mechanical instability. Eur Spine J 1998; 7:484492.

3. Kristjansson E, Leivseth $G$, Brinckmann $P$ et al. Increased sagittal plane segmental motion in the lower cervical spine in women with chronic whiplash-associated disorders, grades I-II: A case-control study using a new measurement protocol. Spine 2003; 28:2215-2221.

4. Grob D, Dvorak J, Panjabi MM. External fixator of the cervical spine--a new diagnostic tool. Unfallchirurg 1993; 96:416-421.

5. Ebraheim NA, Xu R, Ahmad $M$ et al. The effect of anterior translation of the vertebra on the canal size in the lower cervical spine: A computer-assisted anatomic study. J Spinal Disord 1997;10:162-166.

6. Holmes A, Han ZH, Dang GT et al. Changes in cervical canal spinal volume during in vitro flexion-extension. Spine 1996; 21: 1313-1319.

7. Ebraheim NA, An HS, Xu R et al. The quantitative anatomy of the cervical nerve root groove and the intervertebral foramen. Spine 1996; 21:1619-1623.

8. Humphreys SC, Hodges SD, Patwardhan A et al. The natural history of the cervical foramen in symptomatic and asymptomatic individuals aged 20-60 years as measured by magnetic resonance imaging. A descriptive approach. Spine 1998; 23:21802184.

9. Dvorak J, Froehlich D, Penning $L$ et al. Functional radiographic diagnosis of the cervical spine: flexion/extension. Spine 1988; 13:748-755.

10. White AA 3rd, Johnson RM, Panjabi MM et al. Biomechanical analysis of clinical stability in the cervical spine. Clin Orthop 1975; 109:85-96.

11. Knopp R, Parker J, Tashjian J et al. Defining radiographic criteria for flexion-extension studies of the cervical spine. Ann Emerg Med 2001; 38:31-35.

12. Lin RM, Tsai KH, Chu LP et al. Characteris- tics of sagittal vertebral alignment in flexion determined by dynamic radiographs of the cervical spine. Spine 2001; 26:256261.

13. Hackett GS, HG, Hemwall GA, and Montgomery GA. Ligament and Tendon Relaxation Treated by Prolotherapy. 5 ed. 1993 Oak Brook, IL: Institute in Basic Life Principles.

14. Liu Y, Tipton CM, Matthes RD et al. An in situ study of the influence of a sclerosing solution in rabbit medial collateral ligaments and its junction strength. Connect Tissue Res 1983; 11:95-102.

15. Ongley M, Klein RG, Dorman TA et al. A new approach to the treatment of chronic low back pain. Lancet 1987; 2:143-146.

16. Bordeau Y. Five-year follow-up on sclerotherapy/prolotherapy for low back pain. Manual Medicine 1988; 3:155-157.

17. Klein R, Dorman, TA, Johnson, CD et al. Proliferation injections for low back pain: Histologic changes of injected ligaments and objective measurements of lumbar spine mobility before and after treatment. J Neurol Orthop Med Surg 1989; 10:123126.

18. Schwartz R. Prolotherapy: A literature review and retrospective study. I Neurol Orthop Med Surg 1991; 12:220-223.

19. Klein R, Eek BC, DeLong WB et al. A randomized double-blind trial of dextroseglycerine-phenol injections for chronic, low back pain. I Spinal Disord 1993; 6:2333.

20. Reeves K, Hassanein K. Randomized prospective double-blind placebo-controlled study of dextrose prolotherapy for knee osteoarthritis with or without ACL laxity. Altern Ther Health Med 2000; 6:68-74, 7780.

21. Kayfetz DO. Occipito-cervical (whiplash) injuries treated prolotherapy. Med Trial Tech Q 1963; 9:9-29.

22. Hackett G. Prolotherapy in Whiplash and Low Back Pain. Postgrad Med 1960; 27: 214-219. 